\title{
From Experience to Metaphysics: On Experience-based Intuitions and their Role in Metaphysics
}

\author{
JIRI BENOVSKY* \\ University of Fribourg
}

\begin{abstract}
Metaphysical theories are often counter-intuitive. But they also often are strongly supported and motivated by intuitions. One way or another, the link between intuitions and metaphysics is a strong and important one, and there is hardly any metaphysical discussion where intuitions do not play a crucial role. In this article, I will be interested in a particular kind of such intuitions, namely those that come, at least partly, from experience. There seems to be a route from experience to metaphysics, and this is the core of my interest here. In order to better understand such 'arguments from experience' and the kind of relationship there is between this type of intuitions and metaphysical theories, I shall examine four particular cases where a kind of experience-based intuition seems to motivate or support a metaphysical theory. At the end of the day, I shall argue that this route is a treacherous one, and that in all of the four cases I shall concentrate on, phenomenological considerations are in fact orthogonal to the allegedly 'corresponding' metaphysical claims. An anti-realist view of metaphysics will emerge.
\end{abstract}

\section{$\$ 1$.}

Metaphysical theories are often counter-intuitive. Some tell us that there are weird material macroscopic objects, like an object made up from the top half of the Eiffel Tower, the north face of Everest, the last living polar bear, and Socrates' nose. Others tell us that time does not pass and that ordinary objects - including ourselves - do not persist through time, or for that matter, that time does not exist and ordinary objects - including ourselves - do not exist. Some claim that there is no universe around us at all and that the world we seem to be living in is actually akin to a dream. Yet others tell us that not only our universe, time, us, and weird macroscopic objects $d o$ exist, but that so do infinitely many other counterpart universes, as real as our own.

When facing such strong and striking claims, as a metaphysician, one may wish to react in various ways. One may want to reject these claims (or, at least, incredulously stare at them). More daringly, one may want to reject one's intuitions that these claims violate. Or, one may try to show that these claims actually do not violate any (real and good) intuitions. Alternatively, one may also try to show that one's 
opponent's theories are as counter-intuitive as one's own. Sometimes, things go the other way around: one starts from a (real and good) intuition, and develops a metaphysical theory based on it.

One way or another, the link between intuitions and metaphysics is a strong and important one, and there is hardly any metaphysical discussion where intuitions do not play a crucial role. In this article, I will be interested in a particular kind of such intuitions, namely those that come, at least partly, from experience. (Actually, it seems to me that most, if not all, of our intuitions are such, but I shall not argue for this claim here.) There seems to be a route from experience to metaphysics, and this is the core of my interest here. In order to better understand such 'arguments from experience' and the kind of relationship there is between this type of intuitions and metaphysical theories, I shall examine four particular cases where a kind of experience-based intuition seems to motivate or support a metaphysical theory. At the end of the day, I shall argue that this route is a treacherous one, and that in all of the four cases I shall concentrate on, phenomenological considerations are in fact orthogonal to the allegedly 'corresponding' metaphysical claims.

\section{\$2.}

Before making any general claims, and before really saying anything about intuitions as such, I shall start by examining four cases - to be found in Table 1 in the appendix at the end of this article - where one could think that there is an argument in favour of a metaphysical theory coming from experience. ${ }^{1}$ I will only quickly discuss the first two cases - where, I think, the point I want to highlight is rather obvious - and then look more in detail at the other two.

All four of these 'arguments' are bad ones. Take the first case, and call the putative object made up of the top half of the apple and the left half of the table "Bernard". What the defender of unrestricted mereological composition (who'd embrace this type of argument) could want to say is that we see Bernard, it's there, just in front of us. We can touch it, and smell it as well. So, there is no reason for saying that only the apple and the table exist, while Bernard does not. We experience all three objects equally well, so we should treat them accordingly as ontologically equal. Perhaps this is a simplified picture of what a friend of this line of argument could say, and of course not everybody would agree on the datum - namely, that we see Bernard equally well as the apple and the table. Indeed, this line of argument can be reversed and can be taken to purportedly show the exactly opposite claimthat since we do not perceive Bernard in the same way we do perceive the other two objects, we should not put it ontologically on a par with them.

But, as Merricks (2001, p. 9) rightly remarks, these considerations about our perceptions of Bernard, if taken as leading to the doctrine of unrestricted (or restricted) mereological composition (depending on what you think of the perceptual datum), is entirely misguided: our visual, olfactory, and tactile evidence would be exactly the same whether Bernard existed or not. That is, whether the top half of the apple and the left half of the table compose an object is an ontological question, and a mereological claim, which is entirely neutral with respect to what we see. Our 
visual phenomenal experience when contemplating this scene would be exactly the same whether Bernard existed (as a sui generis object) or not, simply because our visual phenomenal experience is caused by light reflected by the objects in front of us, and it would be reflected in exactly the same way whether Bernard were an object or not. The questions surrounding Bernard's existence should then be settled by other than perceptual means; for instance, by invoking philosophical arguments such as Lewis' (1986, p. 212-213) who claims that restricted composition should be rejected because it entails metaphysical vagueness.

There are many other cases of this kind populating metaphysical debates. About the statue and the lump case, for instance, Maclaurin and Dyke $(2012, \S 5)$ say: "We can talk about whether the statue and the lump of clay are really two objects or actually just one, but the singularity or duality of the statue and the lump is not something that can impinge on human experience." Again, I guess their idea is the same as above: whether there are two objects or only one, our visual phenomenal experience would be exactly the same.

The case Merricks (2001, p. 8) is interested in concerns eliminativism about macroscopic objects - see the second column of my table of examples above. Eliminativists claim that there are no apples and no tables, only fundamental components (particles, properties, or whatever one takes to be the fundamental constituents of reality) arranged applewise or tablewise. But, the objector could say, we see the table and the apple, they're right there, just in front of us. The unfriendly objector could then point to eliminativism as to a doctrine that is almost absurd and entirely in conflict with any good common sense. The less unfriendly objector could want to stress that there is a strong tension between the eliminativist's claim about the world and our experience of the world; the eliminativist, then, owes us at the very least a good explanation of why there is such a tension, and why we should reject what our eyes see rather than what the eliminativist wants to say.

One way to go for the eliminativist could be to show that eliminativism is such a theoretically virtuous doctrine that indeed we should reject our intuitions and common sense beliefs about the world based on our experience of apples and tables. Such argumentative strategies are of course often used in metaphysics. But the more adequate strategy is to realize that in fact there is no tension at all. As before, what we see and what the world is like are just two entirely orthogonal issues, simply because our visual phenomenal experience would be the same whether there were apples and tables in front of us or whether there were 'only' fundamental components arranged applewise and tablewise. Apples and fundamental components arranged applewise both reflect light in the very same way, and consequently the way the world 'hits' our perceptual system would be exactly the same in both cases. Thus, our phenomenal experience of the world, which is an experience as of apples and as of tables, is entirely neutral with respect to the existence of apples, tables, or arrangements of fundamental components. As Merricks puts it, fundamental components arranged applewise can do just about anything apples can do: they can be seen, purchased, eaten, and so on. Thus, there is no tension at all between the eliminativist's picture of the world and our phenomenal experience. 


\section{$\S 3$.}

My third example concerns the case of our temporal experience in relation to the A-theory and B-theory of time. In short, B-theory claims that time is very much space-like - a further dimension in which things can be located by bearing relations of 'being earlier than', 'being later than', and 'being simultaneous with' to each other-while A-theory claims that time passes, that there is a genuine ontological distinction between the present time on the one hand and past and future times on the other hand, and that time is very much not like space. Of course, there are many variants of both views, and very different ones, ${ }^{2}$ the relevant difference between the two competitors for me in what follows is just that one of them claims that time passes, or flows, while the other does not.

Indeed, the A-theory of time, or at least some versions of it, certainly has as one of its core motivations the idea that it only - as opposed to B-theory - can account for the fact that time passes or flows, a fact that is taken to be apparent in our experience of time as of passing. In this case, many have thought, and some have explicitly expressed, ${ }^{3}$ the idea that there is a route from experience to metaphysics, as for instance Brad Skow $(2009, \S 4)$ : "I cannot survey all the motivations philosophers have had for the moving spotlight theory. But the motivation that I like best appeals to the nature of our conscious experience". Schematically speaking, the argument goes like this: we experience time as passing (this is given to us in phenomenal experience); B-theory cannot account for temporal passage; A-theory can; thus A-theory is a better theory. A metaphysical conclusion is thus drawn from considerations about our phenomenology. Or, at the very least, the friend of this line of argument says, there is a strong tension between the conception of a B-theoretic 'static' world and our experience of the world which is dynamic - and so the worse for B-theorists.

But even if perhaps in a more subtle and more controversial way, this case is in fact analogous to the two cases we have seen above (about composition and eliminativism) in the sense that issues concerning our temporal experience and issues about the nature of time are here again entirely orthogonal. Indeed, as we shall see below, our experience of temporal passage can be accounted for in B-theoretic terms as well as in a dynamic A-world. Our experience of the world is thus neutral with respect to these two theories, and consequently there is no argument from experience to either B-theory or A-theory. Let us see how this works.

The first thing to note is that we actually never experience the flow or passage of time directly, we 'only' experience it by having experiences of succession and change. In agreement with Robin Le Poidevin ${ }^{4}$ and L. A. Paul, ${ }^{5}$ it seems to me correct to say that if we did not perceive any change at all (including change in our own thoughts), it would not seem to us that time is passing. The way we measure time also always involves measuring change: we only measure how much time has elapsed by observing changes happen (for instance, the movement of sand falling through a sandglass).

Now, our temporal experience certainly often is, phenomenologically speaking, an experience as of change, and consequently as of temporal passage. This is often 
so in perception of movement. But such experiences can often be illusory, in the sense that in many cases it appears to us in our phenomenal experience that (i) there is movement when there is not, and that (ii) there is no movement when there is.

Take the case of the hour hand on a mechanical watch: it moves so slowly that we just do not perceive it as moving. We can of course observe that it has moved, if we look at it after some time, but such a "perception" is no experience of movement at all. Thus, we have a case where there is movement, but we do not experience it as such, simply because the hour hand's continuous movement is far too slow for us to be able to perceive it. Indeed, what we realize here, is that our capacities to notice change and movement have a lower limit and that anything that moves too slowly will not be registered by our perceptual system as moving.

Take now the opposite case, where there is no genuine movement but we do have a phenomenal experience as of movement. Paul (2010) discusses in detail such cases when she, relevantly to our discussion here, defends an account of how our temporal experience arises from the way our brains interpret cognitive inputs from series of static events. To do that, she provides us with some well-known experiments from experimental psychology and cognitive science such as this simple one: "[...] an interesting and empirically well-documented fact about our experience-namely, the illusion we have when, first, one small dot is shown on the left-hand side of a computer screen and then, very quickly, that dot disappears and a small dot is shown on the right-hand side of a computer screen. Then, the right-hand dot disappears, and the left-hand dot appears, again and again, in rapid succession. Even when we are told that what the computer is actually doing is merely blinking different dots on alternating sides of the screen, as long as the succession is rapid enough and spatiotemporally close enough, the effect is that we have the illusion of the dot moving back and forth across the screen. This is what cognitive scientists usually describe as 'apparent motion'." (Paul (2010, p. 15-16)) There are many such examples of apparent motion, not the least of them being the case of cinema where a series of static images is shown quickly enough — but not too quickly - for us to have an experience of movement when we look at it.

What we see here is that a succession of appropriately linked experiences gives rise to an experience of movement, where "appropriately" means that the successive experiences must occur at an appropriate speed, namely, within the lower and upper temporal limits of our perceptual system's capacities - and, crucially, regardless of whether there is genuine movement or not. As Paul (2010, p. 16) argues further, the having of such-and-such experience - as of movement or not - is totally independent of whether we know that there is a genuinely moving object in front of us that we are perceiving or whether we know that we find ourselves confronted with an illusion of genuine movement (like in the case of the moving dot on the computer screen or in the case of cinema). The 'apparent motion' illusion persists independently of whether or not we are aware of its illusory nature. The reasons behind all this is that our brain first interprets the successive inputs it gets from the world, on a psycho-neurological but not phenomenal level, before it produces a conscious phenomenal experience. It 'stores and computes' a number of inputs, and only after a process of interpretation does it give rise to an experience-which 
will be an experience as of movement or not, independently of whether there was genuine movement at the origin of the inputs or not. This is why we never have an experience of singular static frames in the case of film projection in the cinema: our brain 'creates' for us an experience of movement precognitively before, so to speak, it reaches the phenomenal level of our experience.

Thus, whether we find ourselves in an A-world that contains 'genuine' change and movement, or whether we live in a B-world that contains a series of static stages which are given to us at an appropriate speed, our phenomenal experience, such as it is produced by our brains and our perceptual systems, will be an experience as of movement (or not, if the A-changes are too slow or too fast, or if the B-series are given to us too slowly or too quickly). As before in the case of mereological composition and eliminativism, what we see here is that our phenomenal experience is entirely neutral with respect to what the world is like. No metaphysical conclusions - either in favour of A-theory or B-theory - can thus be drawn from the nature of our experience.

\section{$\S 4$.}

The fourth and last example I want to discuss concerns the way we perceive, and conceive of, the identity of ordinary macroscopic objects through time. The intuitive idea behind endurantism is that an apple that is first red and juicy and later brown and rotten is one and the same object that is changing. Very often this idea is taken to be some sort of philosophically intuitive constraint on the notion of change or the notion of a persisting ordinary object, and endurantism is often claimedeven if not explicitly - to be the 'intuitive' or the 'common sense' view, contrary to perdurantism, as the following citations illustrate.

"No one else [than the perdurantist] would say that only [temporal] parts of Sir Edmund Hilary and Tenzing Norgay climbed only a part of Everest in 1953. The rest of us think those two whole men climbed that one whole mountain, and that all three parties were wholly present throughout every temporal part of that historic event". (Mellor (1998, p. 86))

"[...] outside philosophical seminars a four-dimensionalist never says 'a two-hour phase of me last night was a waking phase'; he says, with the rest of us, 'I was awake for two hours last night'." (Simons (2000, p. 62))

"The [four-dimensionalist's] metaphysics yields that if I have had exactly one bit of chalk in my hand for the last hour, then there is something in my hand which is white, roughly cylindrical in shape, and dusty, something which also has a weight, something which is chalk, which was not in my hand three minutes ago, and indeed, such that no part of it was in my hand three minutes ago. As I hold the bit of chalk in my hand, new stuff, new chalk keeps constantly coming into existence ex nihilo. That strikes me as obviously false." (Thomson (1983, p. 213))

In some sense, which is very often not precisely specified, endurantism is supposed to be the obvious, common sense, acceptable, intuitive view, while 
perdurantism is supposed to violate some strong intuitions we have about the world - or at least this is how I understand such statements that populate the discussion between perdurantists and endurantists. Some perdurantists themselves agree on this "intuitive datum", while they just think that this is a case where we should abandon our intuitions, and revise our common sense beliefs, because they take perdurantism to be a theoretically strong and virtuous view.

Now, what are these pro-endurantist intuitions about? Where do they come from? Are they revealing some philosophically deep conceptual truth? As we shall now see, they are not-rather they are mere consequences of the (contingent) way our perceptual system works, and what's intuitive in the common sense endurantist idea is rather something that arises from the character of our ordinary phenomenal experience of moving and changing macroscopic objects. In an article stemming from results obtained in experimental psychology experiments, Scholl (2007) discusses what could be an explicit argument in favour of endurantism based on the nature of our phenomenal experience of macroscopic objects:

"Endurance theories of persistence, for example, may simply strike many readers as
much more natural and compelling than perdurance $[\ldots]$ theories because endurance
theories are more closely matched to the actual way in which we experience the
world." [...] "Philosophers may think, for example, that they are preferring an en-
durance theory because 'a number of our practices and forms of self-understanding
depend on the idea that there are enduring things' (Haslanger (2003, p. 351)-but
I suggest that what many of these 'practices' and 'forms of self-understanding' may
come down to in practice are the results of the mental machinery we have that is
devoted to computing enduring representations of objects over time." Scholl ( 2007 ,
p. 583)

The general idea supported by Scholl's findings in the field of experimental psychology is, in short, the following. We want to be endurantists because we have a strong intuition in favour of endurantism, and we have that intuition because of the way we experience the world. But the way we experience the world is (i) contingent (the way our brain and our perceptual system are built - "hard-wired"is contingent), and (ii) fully compatible with the world being a perdurantist world. As in the other cases we have already seen above (composition, eliminativism, Atheory, B-theory), here again our experience is in fact neutral with respect to the way the world is, and so are then our intuitions that stem from this experience. (Obviously, this is not to say that endurantism is false-it's just that it cannot be argued for and it should not be motivated by using this experiential and intuitive basis.) To see this in more detail, let us consider one of the experiments discussed by Scholl (2007, p. 567) where the way we experience spatio-temporal continuity of moving objects is studied.

In a 'multiple object tracking' (MOT) experiment, observers are first given a series of objects where some of them are marked as being "targets" (by shortly once blinking) (see Figure 1): 


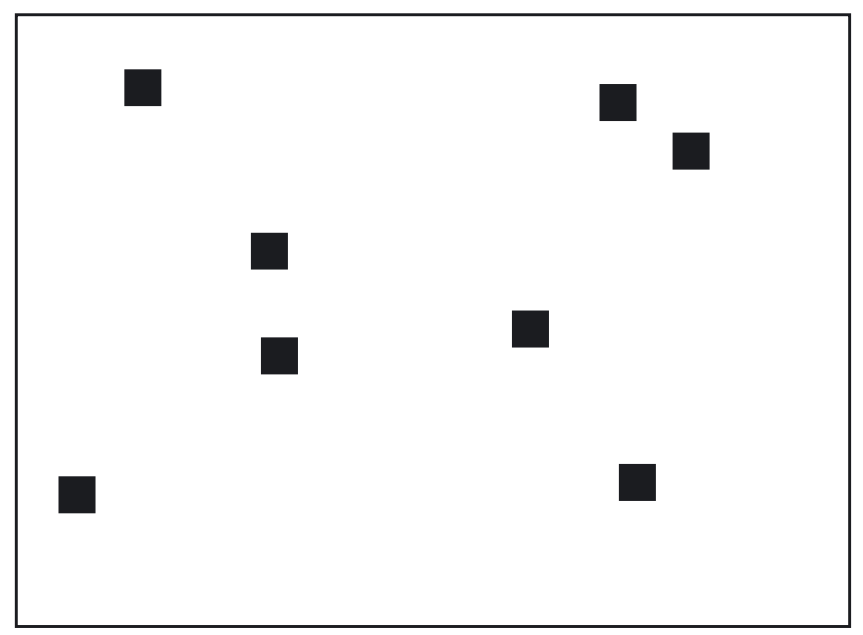

Figure 1. Basic MOT experiment. (Animations of this and the following experiment can be downloaded at http://www.yale.edu/perception/Brian/demos/MOT-Occlusion.html)

The objects then start moving in an unpredictable way in all directions, and when they stop, observers must tell which are the targets and where they are. In a second stage of the experiment, occluders are added to it (see Figure 2):

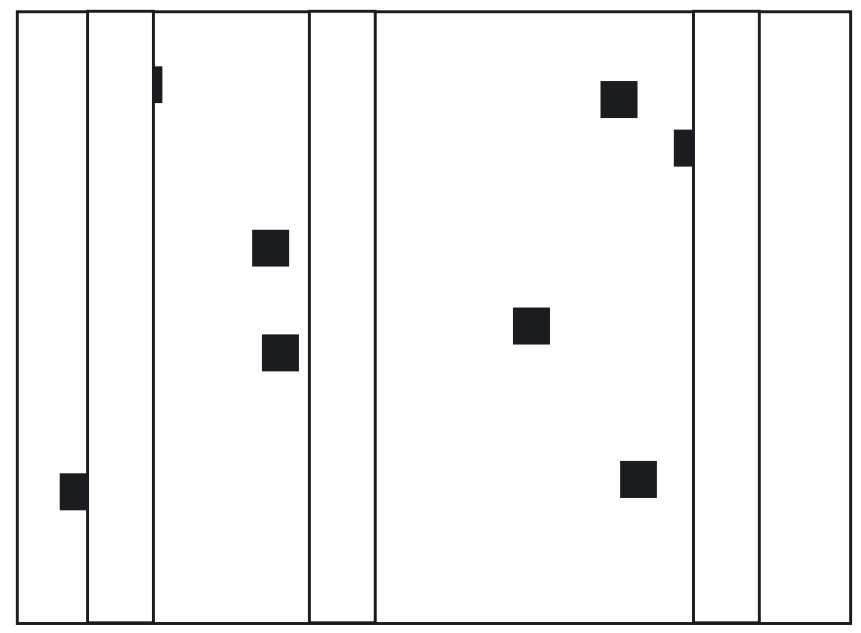

Figure 2. MOT experiment with occluders

In this scenario, which brakes the spatio-temporal continuity of the trajectory of the moving objects, the targets often disappear behind occluders. As Scholl (2007, p. 567) puts it "objects may not pop into and out of existence, but they do frequently pop into and out of sight". 
What the results of such (and other variants of) MOT experiments show is that observers are very successful at tracking the targets even in cases where disruptions such as occluders are in place, and that we human beings are just made in such a way that we experience the world as a world of objects that remain the same following a principle of spatio-temporal continuity. As Scholl (2007, p. 567) puts it "[the principle of spatio-temporal continuity has] become wired into our minds, and helps to control our experience of objects as persisting in the world". This is not only so when various kinds of occluders are introduced, but also even when observers know that the targets they are supposed to follow and identify as being one and the same object are in fact not one and the same object. Typically, observers are aware of the fact we already encountered in $\S 3$ above that the "objects" on the computer screen are actually just a series of different zones successively lit on the screen (to have a more complex and life-like example in mind, just think of tracking an "object" in a movie, where that object often disappears behind occluders, and where you very well know that in fact you are viewing a series of static images projected at 24 images per second). In short, it appears that our perceptual system is made in such a way that we track one moving object and identify it as being one and the same object, even if it frequently disappears our of sight, and even if we know that in fact it is not one object.

Furthermore, the principle of spatio-temporal continuity appears to be the most fundamental one when it comes to how our experience of persistence works. Indeed, spatio-temporal continuity trumps other criteria, as various other experiments showed. Scholl discusses an experiment where one object disappears behind an occluder and a very different object emerges from the other side of the occluder and continues moving. In such cases, if the second object emerges at the same time at which the first object would have emerged had it continued its movement in a continuous way, observers identify it as being one and the same object which underwent qualitative change - even when the change is quite significant (shape, colour, size, ....). Our perceptual system tells us that there is one and the same object being temporarily hidden by an occluder and undergoing change, rather than two objects one of which stays behind the occluder and the other emerges from behind it. Things are different when a temporal delay is introduced between the time when the first object disappears behind the occluder and the time when the second object emerges - in this case, where continuity of motion is disrupted, observers identify the objects as being two different objects. Thus we see that our perceptual system is made so that it provides us with percepts in such a way that spatio-temporal continuity trumps property change-we accept more easily that an object significantly changes its properties, but not so easily that it violates spatiotemporal continuity. To sum up, Scholl (2007, p. 573) says "the results [of these experiments] revealed a temporal same-object advantage", and furthermore, what we see in these cases is that we cannot help but having an experience as of one and the same persisting object - it is "forced upon us" by the way our brain and perceptual system deals with stimuli from the external world ("[...] the principle of spatiotemporal continuity [...] seems to be wired into our minds in a deep way, controlling how we experience the world" (Scholl (2007, p. 569))). 
$\S 5$.

The results of considerations and experiments such as those we have seen in $\S 3$ and $\$ 4$ above lead then to an understanding of our experience of movement, persistence, and diachronic sameness of ordinary material objects as being such that we cannot help but having it, given the way our perceptual system is built, even in cases where there is no motion, no persistence, and no sameness. We have experiences as of movement, change, persistence, and diachronic sameness, even where there is none. Thus, as before, we see here that the phenomenal character of our experience is one thing, and the metaphysical nature of the world is another. Whether the world is a perdurantist B-theoretic one or an endurantist A-world, our phenomenal experience would still be the same. Relevantly, we learn from $\S 3$ and $\S 4$ that we would have an experience as of persistence of one and the same object identical through time and of time as passing, even in a static perdurantist B-world where there is 'only' a series of different numerically distinct objects (temporal parts, or stages) located in a static B-series. And of course, we would have the same experience also in a dynamic endurantist A-world (or in a perdurantist A-world, or an endurantist B-world, etc.). In short, both a series of successive temporal parts (or stages) in a B-world and an enduring object in an A-world would produce in us, given our perceptual system, the same phenomenal experience.

Now, I would like to suggest that things go also the other way around-though, for obvious reasons, this claim cannot be backed up here by any empirical research. Indeed, until now I argued in favour of the claim that our experience would be the same in different conditions. But it seems to me also very plausible that in the same conditions (in one and the same world) different types of conscious beings, with different perceptual systems, would have different experiences of the same metaphysical reality. I will not venture here into a complex discussion about how some animals on Earth experience persistence, movement, temporal passage, or whether they have anything like 'intuitions' in favour of unrestricted mereological composition or eliminativism. But it does seem entirely plausible to me to conceive of alien conscious beings populating some other part of our world who have very different bodies (say, they are made of gas) and very different perceptual systems and brains, and who, as a consequence, have entirely different experiences from our own, of the same universe.

\section{$\S 6$.}

Gas-based aliens left aside, here are the two claims that I wish to defend: (i) the phenomenal character of our experience is neutral with respect to the nature of metaphysical reality, and (ii) at least some of our intuitions concerning the relevant notions and claims are based on our phenomenal experience and, consequently, are not good guides for the metaphysician to follow.

Let me try to say a bit more about (ii). Indeed, it seems that what is often taken to be an intuition (say, in favour of endurantism, or in favour of A-theory) is simply a result of how we experience the world. We have seen above several 
examples where our experience seems to back up a metaphysical theory, but we have seen that this is no more than a seeming and a possibly misleading piece of alleged evidence if favour of one or another metaphysical claim. Consequently, one has to be very careful about what one calls an "intuition" and about where such an intuition comes from. If - as I think is indeed the case in the various examples I discussed above - such so-called intuitions are in the end just manifestations of how we (contingently) experience the world, then one must take care not to draw any metaphysical conclusions, or to motivate a metaphysical view, based on such 'intuitive data'.

The difficulty is then to identify which of the 'intuitions' we have are deceitfully such, and which (if any) are immune to this worry-and this is where work in the field of cognitive science and experimental psychology, as we have seen in the case of Scholl (2007), can be a valuable contribution to the philosophical debate, since it allows us to either discard some of our 'intuitions' as being misleading, or at least to proceed with extreme caution when appealing to them when doing metaphysics. For the metaphysician, there is a threat there. There is the risk that at the end of such an evaluative procedure, where our 'intuitions' are scrutinized and their potentially misleading character evaluated, we end up realizing that many, or even most, of what we took to be deep intuitions turn out to be mere constructions from the way we contingently happen to experience the world. This becomes then immediately problematic for metaphysics as a philosophical discipline, since in many domains of metaphysics intuitions play a central role in both theory construction and theory evaluation. Often, in metaphysics, we just don't have at our disposal any other data than our so-called intuitions. What to do?

\section{$\S 7$.}

This last section will be quite speculative, and I will be happy enough if you follow me only in what I said above and stop here. But I think that one possible and very natural reaction to these worries could be a form of anti-realism. We could simply accept that the best we can do when doing metaphysics is to understand the world as it is given to us (perceptually and conceptually), and not as it is. Perhaps, it is time to think better of such a Kantian view, despite its unpopularity. To be more precise, one way to understand such a view would be to insist that metaphysics does not tell us how the world is, rather it tells us what our concepts are like (this claim is to be distinguished from the claim that metaphysics is conceptual analysis - a very different claim which one does not need to endorse here). ${ }^{6}$

According to this picture of the way metaphysics works, we start with the concepts - and, yes, intuitions - we have (like the concept of an ordinary material persisting object, and experiential and intuitive data associated with it), where such concepts can, in principle, both be given to us a priori or from experience. Intuitions, as we have seen, seem to come often from the phenomenal character of our experience. These are the only data we can possibly have when it comes to many metaphysical issues (on which physics and other sciences are simply silent). As we advance in the metaphysical enterprise, we then want to better understand 
these concepts (and percepts, and intuitions), and we want to understand the connections and relations between them. To this end, we may use empirical science. Physics can prove useful when it comes to some metaphysical debates (perhaps, the presentism vs. eternalism controversy), but not in many other cases (say, the tropes vs. universals debate, statues and lumps, eliminativism, mereological composition, personal identity, and many other). Experimental psychology and cognitive science, as we have seen above, can prove to be extremely useful in many cases, mostly to assess the value of the intuitive and experiential data we started with. Finally, as metaphysicians, we may want to (need to) introduce new theoretical concepts (say, bare particulars or relations of compresence, or temporal counterpart relations, etc.). In the end, this procedure gives then rise to metaphysical theories which are organizations and systematizations of our concepts, the surviving old ones as well as the new ones. And, crucially, that's it. That's as far as we can go. Friends of realism will certainly raise their eyebrows, and protest against such a defeatist way of conceiving of what metaphysics is and what it can do. What about the world? But then, they need to say what kind of data-other than (possibly) misleading intuitions, which will often turn out to be mere constructs from the contingent phenomenal character of our experience - they can use to go further. I am not saying, as others do, ${ }^{7}$ that given the lack of trustworthy data, metaphysics is a futile discipline and that it should be discontinued, but I do not share the realist's optimism either-simply because it seems to me ungrounded. ${ }^{8}$

\section{Notes}

*www.jiribenovsky.org

${ }^{1}$ In these examples, and throughout this article, I will simply assume that hard-core scepticism about the existence of the external world is false. I will assume that there is a world existing independently of us, and that in some way or another we have experiences of it.

${ }^{2}$ Defenders of one version or another of A-theory include Lowe (1998), Bigelow (1996), Merricks (1999), Markosian (2004), Craig (2000), Zimmerman (1996, 1998, 1997), Prior (1970, 2003b), and Chisholm (1990a, 1990b). Defenders of one version or another of B-theory include Quine (1960), Lewis (1976), Mellor (1981, 1998), Sider (2001), Le Poidevin (1991), and Oaklander (1991).

${ }^{3}$ See for instance Williams (1951, pp. 465-66) and Maudlin (2007, pp. 135, 142).

4 "In fact, it seems odd to say that we see, hear or touch time passing. And indeed, even if all our senses were prevented from functioning for a while, we could still notice the passing of time through the changing pattern of our thought." Le Poidevin (2009)

5 "[...] if we were in an entirely static environment where there were no contrasts between property instances (this would have to include no contrasts with respect to properties of my thoughts), then it would seem to us as though time were standing still. And, indeed, I think this is a very plausible supposition." (L. A. Paul (2010, p. 23))

${ }^{6}$ There are two central claims typically endorsed by friends of conceptual analysis which I am not very sympathetic with and which are not needed here: first, the claim that metaphysics is a purely armchair a priori affair, and second, relevantly to our discussion, the weight defenders of conceptual analysis put on the role our intuitions play in metaphysics. On conceptual analysis and the role of intuitions in philosophy see, inter alia, Bealer (1987, 1998), Chalmers (1996), and Jackson $(1994,1998)$.

${ }^{7}$ See Ladyman and Ross (2007), and for an excellent discussion of this view see Maclaurin and Dyke (2012).

${ }^{8}$ I am very grateful to Baptiste Le Bihan, Michael Esfeld, Laurie Paul, and Gianfranco Soldati for discussions and comments which greatly helped me to write this article. 


\section{Appendix}

Table 1. Alleged 'arguments from experience'.

\begin{tabular}{|c|c|c|c|c|}
\hline & Case 1 & Case 2 & Case 3 & Case 4 \\
\hline $\begin{array}{l}\text { Phenomenal } \\
\text { Experience }\end{array}$ & $\begin{array}{l}\text { I see an apple on a } \\
\text { table. I see an apple, } \\
\text { and I see a table. But } \\
\text { there is also this } \\
\text { object: top half of } \\
\text { the apple + left half } \\
\text { of the table. I see } \\
\text { this object as well, } \\
\text { it's right there, in } \\
\text { front of me. }\end{array}$ & $\begin{array}{l}\text { I see an apple on } \\
\text { a table. }\end{array}$ & $\begin{array}{l}\text { I experience time } \\
\text { as passing, and } \\
\text { apples and tables } \\
\text { as changing from } \\
\text { being present to } \\
\text { being past (for } \\
\text { instance, when } \\
\text { they are } \\
\text { destroyed). }\end{array}$ & $\begin{array}{l}\text { I see that the apple on } \\
\text { the table persists and } \\
\text { changes through time. } \\
\text { It is first red and juicy } \\
\text { and later brown and } \\
\text { rotten. But it's still the } \\
\text { one and the same } \\
\text { apple at which I was } \\
\text { looking the whole time } \\
\text { while it was changing. } \\
\text { I can see this one } \\
\text { object changing. }\end{array}$ \\
\hline $\begin{array}{l}\text { 'Argument from } \\
\text { Experience' in } \\
\text { favour of this } \\
\text { Metaphysical } \\
\text { Theory }\end{array}$ & $\begin{array}{l}\text { Unrestricted } \\
\text { mereological } \\
\text { composition. }\end{array}$ & $\begin{array}{l}\text { There are apples, } \\
\text { and there are } \\
\text { tables. They exist. }\end{array}$ & A-theory. & Endurantism. \\
\hline $\begin{array}{l}\text { Competing } \\
\text { Metaphysical } \\
\text { Theory }\end{array}$ & $\begin{array}{l}\text { Restricted } \\
\text { mereological } \\
\text { composition. }\end{array}$ & \begin{tabular}{|l|} 
Eliminativism \\
about \\
macroscopic \\
objects. There \\
are no tables, no \\
apples, only \\
fundamental \\
particles \\
arranged \\
tablewise and \\
applewise.
\end{tabular} & B-theory. & $\begin{array}{l}\text { Perdurantism. Not one } \\
\text { object wholly present } \\
\text { at different times } \\
\text { undergoing change, } \\
\text { but a series of } \\
\text { different objects (stage } \\
\text { view), or a series of } \\
\text { different objects } \\
\text { (temporal parts) } \\
\text { making up a } \\
\text { temporally bigger } \\
\text { object (the apple). }\end{array}$ \\
\hline
\end{tabular}

\section{References}

BEALER, G. 1987. The Philosophical Limits of Scientific Essentialism. Philosophical Perspectives 1:289365.

BEALER, G. 1998. Intuition and the Autonomy of Philosophy. In DePaul, M. and Ramsey, W., eds., Rethinking Intuition. Oxford: Rowman \& Littlefield Publishers.

BIGELOW, J. 1996. "Presentism and Properties", in Tomberlin (ed.), Philosophical Perspectives: Vol. 10, Malden, Mass.: Blackwell.

CHALMERS, D. 1996. The Conscious Mind: In Search of a Fundamental Theory. Oxford University Press.

CHISHOLM, R. 1990a. "Events Without Times: An Essay On Ontology", Noûs 24:413-428.

CHISHOLM, R. 1990b. "Referring to Things That No Longer Exist", in Tomberlin (ed.), Philosophical Perspectives 4:545-556.

CRAIG, W. L. 2000. The Tensed Theory of Time. Dordrecht: Kluwer.

HASLANGER, S. 2003. Persistence through time. In Loux and Zimmerman (eds), Oxford Handbook of Metaphysics. Oxford: Oxford University Press, pp. 314-354.

JACKSON, F. 1994. Armchair Metaphysics. In Jackson, F. 1998. Mind, Method, and Conditionals: Selected Essays. London: Routledge, pp. 154-76.

JACKSON, F. 1998. From Metaphysics to Ethics. Oxford: Oxford University Press. 
LADYMAN, J. and ROSS, D. 2007. Every Thing Must Go: Metaphysics Naturalised. Oxford: Oxford University Press.

LE POIDEVIN, R. 1991. Change, Cause, and Contradiction. London: Macmillan.

LE POIDEVIN, R. 2009. The Experience and Perception of Time. In Stanford Encyclopaedia of Philosophy, online.

LEWIS, D. 1976. "The Paradoxes of Time Travel", American Philosophical Quarterly 13:145-52.

LEWIS, D. 1986. On the Plurality of Worlds. Blackwell Publishers.

LOWE, E. J. 1998. The Possibility of Metaphysics. Oxford: At the Clarendon Press.

MACLAURIN, J. and DYKE, H. 2012. What is analytic metaphysics for? Australasian Journal of Philosophy 90(2):291-306.

MARKOSIAN, N. 2004. "A Defense of Presentism", in Zimmerman (ed.), Oxford Studies in Metaphysics: Volume 1, Oxford: Oxford University Press.

MAUDLIN, T. 2007. The Metaphysics Within Physics. Oxford University Press.

MELLOR, D. H. 1981. Real Time. Cambridge: Cambridge University Press.

MELLOR, D. H. 1998. Real Time II. London: Routledge.

MERRICKS, T. 1999. "Persistence, Parts, and Presentism", Noûs 33:421-438.

MERRICKS, T. 2001. Objects and Persons. Oxford University Press.

OAKLANDER, N. 1991. "A Defense of the New Tenseless Theory of Time", Philosophical Quarterly 41:26-38.

PAUL, L. A. 2010. "Temporal Experience”, Journal of Philosophy 107 (7).

PAUL, L. A. 2012. "Metaphysics as Modeling: The Handmaiden's Tale", Philosophical Studies 160:1-29.

PRIOR, A. N. 1970. "The Notion of the Present", Studium Generale 23:245-48.

PRIOR, A. N. 2003a. Papers on Time and Tense. New Edition, Per Hasle, Peter Ohrstrom

PRIOR, A. N. 2003b. "Changes in Events and Changes in Things", in Prior, 2003a, pp. 7-19.

QUINE, W. V. O. 1960. Word and Object. Cambridge, Mass.: M.I.T. Press.

SCHOLL, B. J. 2007. "Object Persistence in Philosophy and Psychology", Mind and Language 22 (5):563-591.

SIDER, T. 2001. Four-dimensionalism. Clarendon Press.

SIMONS, P. 2000. "Continuants and occurrents", The Aristotelian Society Supplementary Volume 74: $59-75$.

WILLIAMS, D. C. 1951. "The Myth of Passage", Journal of Philosophy 48 (15):457-472.

ZIMMERMAN, D. 1996. "Persistence and Presentism", Philosophical Papers 25:115-126.

ZIMMERMAN, D. 1997. "Chisholm and the Essences of Events", in: Lewis Hahn (ed.), The Philosophy of Roderick M. Chisholm, Peru, Illinois: Open Court, pp. 73-100.

ZIMMERMAN, D. 1998. "Temporary Intrinsics and Presentism", in Persistence, ed. by Sally Haslanger and Roxanne Marie Kurtz. Cambridge, Mass.: M.I.T., 2006, pp. 404-424. 